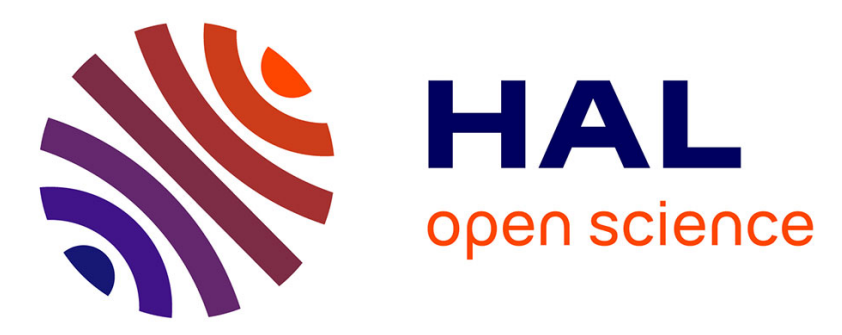

\title{
Modelling of initial fatigue crack growth and crack branching under fretting conditions
}

\author{
Valérie Lamacq, Marie-Christine Baietto
}

\section{To cite this version:}

Valérie Lamacq, Marie-Christine Baietto. Modelling of initial fatigue crack growth and crack branching under fretting conditions. Fatigue and Fracture of Engineering Materials and Structures, 1999, 22 (6), pp.535-542. 10.1046/j.1460-2695.1999.00173.x . hal-01951928

\section{HAL Id: hal-01951928 \\ https://hal.science/hal-01951928}

Submitted on 7 Jul 2021

HAL is a multi-disciplinary open access archive for the deposit and dissemination of scientific research documents, whether they are published or not. The documents may come from teaching and research institutions in France or abroad, or from public or private research centers.
L'archive ouverte pluridisciplinaire HAL, est destinée au dépôt et à la diffusion de documents scientifiques de niveau recherche, publiés ou non, émanant des établissements d'enseignement et de recherche français ou étrangers, des laboratoires publics ou privés. 


\title{
Modelling of initial fatigue crack growth and crack branching under fretting conditions
}

\author{
V. LAMACQ and M.-C. DUBOURG \\ Laboratoire de M'ecanique des Contacts UMR CNRS 5514, INSA de Lyon, Bầtiment 113, 20, Avenue A. Einstein, 69621 Villeurbanne Cedex, France
}

\begin{abstract}
Crack propagation during Stage I, in terms of crack initiation sites and growth directions and crack branching mechanisms under fretting conditions, is investigated using both experimental and theoretical approaches. Fretting tests were conducted on an aeronautical aluminium alloy. Two crack types are observed during Stage I corresponding, respectively, to specific mode I and II conditions. Transition from Stage I to Stage II is characterized for both crack types by a crack branching towards a new propagation direction of $\# 65^{\circ}$ to the specimen surface. Specific parameters linked to mode I and II propagation driving forces are proposed. Crack location and initial growth directions during Stage I are predicted in accordance with these parameters, and are in very good agreement with experimental observations. The conditions governing the transition from Stage I to Stage II are then identified. It is shown that under fretting conditions, cracks branch along a new direction, thereby maximizing the crackopening amplitude.
\end{abstract}

Keywords crack initiation and propagation, crack growth direction, crack branching, modelling.

\section{NOMENCLATURE}

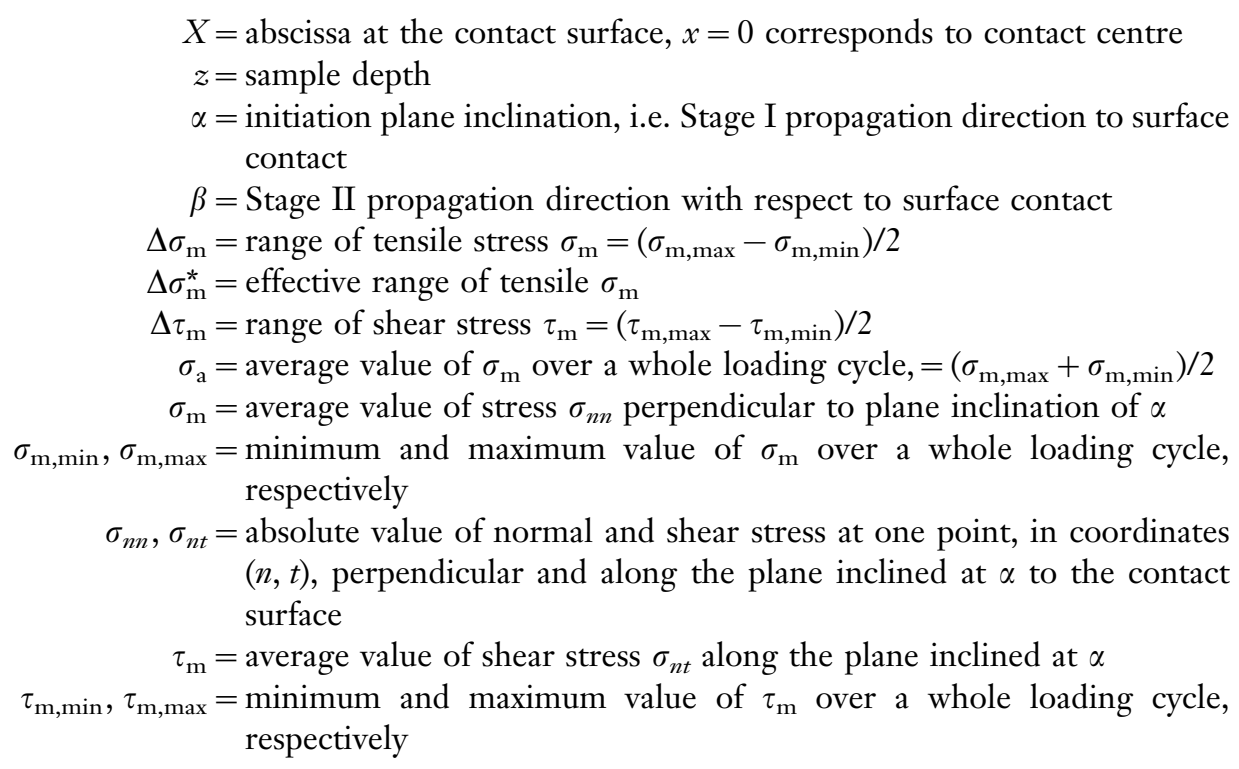

\section{INTRODUCTION}

Fretting wear and fretting fatigue induce both wear and cracking as material degradation responses. The first main degradation response has been related to a fretting regime during fretting tests through the fretting map concept proposed by Vincent et al. ${ }^{1}$ Hence, the running conditions fretting maps (RCFM) and the material response fretting maps (MRFM) describe, respectively, the local fretting regime and the corresponding contact kinematic conditions (sticking, partial slip, gross slip), and the main fretting damage (non-degradation, cracking and particle 
detachment) for normal load-displacement pairings. Cracking induced by fretting has been related by using these maps to partial slip conditions that occur under both the mixed fretting regime and the partial slip regime.

Both experimental and theoretical work have been undertaken to improve our knowledge of crack initiation and propagation. The first tests were conducted on aluminium alloys under partial slip and mixed fretting regimes to obtain experimental data on cracking behaviour. Second, any issues, e.g. (i) the location of the crack nucleation, (ii) the direction taken by the crack during a 'macroscopic' Stage I propagation, (iii) the crack branching during the transition from Stage I to Stage II, and (iv) the direction taken by the crack during Stage II propagation, have been theoretically addressed.

Very few attempts have been made to model these two propagation stages under fretting conditions. The main difficulty raised by such loading is the combination of high stress concentration in the contact area together with a multiaxial stress field. Here, tensile and compressive regions varying in location and intensity develop during the loading cycles, leading to non-proportional mixed mode conditions.

Dang Van et al. ${ }^{2}$ considered elasto-plastic material behaviour to predict initiation sites for industrial components submitted to multiaxial stress fields. Ruiz et al., ${ }^{3}$ Hills and Nowell, ${ }^{4}$ and Lamacq et al. ${ }^{5}$ using different characterizing parameters, nevertheless predicted crack nucleation at rather similar sites. Few studies were carried out to determine initial crack growth direction under fretting fatigue conditions. To reach that goal, Nowell et al. ${ }^{6}$ considered the variation in stress intensity factors, but the applicability of LEFM and the usual stress intensity factor expressions to very short cracks existing in the early growth stage is questionable. By considering the stresses influencing dislocation motion, Yamashita and $\mathrm{Mura}^{7}$ predicted the initial crack growth direction under a repeated oblique force, as initially proposed by Tanaka and Mura. ${ }^{8}$ They needed to consider the influence of an asperity contact to understand the initiation mechanism of pitting cracks experimentally observed. This method, based on a realistic initiation mechanism, seems more appropriate for the prediction of initial crack growth direction.

The approach proposed here rests on this pioneering work. ${ }^{7,8}$ It is further based on the continuum stress field analysis within the subsurface layer. The decisive role of the tensile stress perpendicular to the crack path is emphasized for both mode I and II propagation.

\section{EXPERIMENTS AND OBSERVATIONS}

A new device, called the pre-stressed fretting wear (FWPSS) rig $^{9}$ has been developed to study crack initiation and propagation under fretting conditions. The displacement amplitude being a governing parameter in crack initiation is here controlled, whereas it is not possible during fretting fatigue testing as the displacement varies according to the elongation of the test specimen which itself varies with the applied oscillatory fatigue stress in the specimen. It is therefore very difficult in that case to correlate the crack geometry with the local contact conditions. The FWPSS test has the great advantage that all mechanical parameters can be controlled during loading. The external load is fixed during testing, and the relative displacement between contacting pads is imposed as in the case of the fretting wear (FW). Further, as the RCFMs are almost the same under FW and FWPSS, it is possible to study separately the effects of fretting and external loading on cracking behaviour.

\section{Experimental procedure and conditions}

A brief description of the FWPSS apparatus is shown in Fig. 1. A spherical aluminium (fretting wear specimen) alloy pad of radius $0.3 \mathrm{~m}$ (labelled 2) is pressed against the planar test sample of the same alloy (labelled 1), by a constant normal force, $F_{\mathrm{n}}=1000 \mathrm{~N}$. The spherical body is submitted to a reciprocating microdisplacement, $\delta= \pm 15 \mu \mathrm{m}$, through a piston ring (labelled 3 ), and thus rubs against the planar specimen at a frequency of $5 \mathrm{~Hz}$. This induces an oscillating tangential force, $Q(t)=$ $\pm 950 \mathrm{~N}$, in the contact area. The planar piece is simultaneously submitted to a static external load, $\sigma_{\mathrm{D}}=$ $230 \mathrm{MPa}$ (fretting wear pre-stressed specimen). The ratio between the sticking contact zone diameter, $c$, and the contact zone diameter, $a$, is equal to $c / a=0.9$ [see Fig. 2(c) for notations]. The friction coefficient between the two contacting bodies is very high at a measured value equal to 1.8. Negligible wear of the surface is observed in the annular microsliding zone of the contact. Further, no more significant plastic deformation is observed at the specimen surface at the end of the tests. The specific experimental conditions considered here ${ }^{5}$ induced cracking as the predominant fatigue damage, as observed in the 7075 aluminium alloy.

\section{Fretting crack morphology}

A crack network initiates in the microsliding zone of the contact area (Fig. 3), as revealed by metallographic examination. This network is symmetrical with respect to the contact centre. No difference between the spherical (FW) and planar (FWPS) specimens is observed concerning crack sites and initiation angles. But crack lengths are smaller in the spherical pad. The contact influence is therefore predominant in the initiation pro- 
(a)

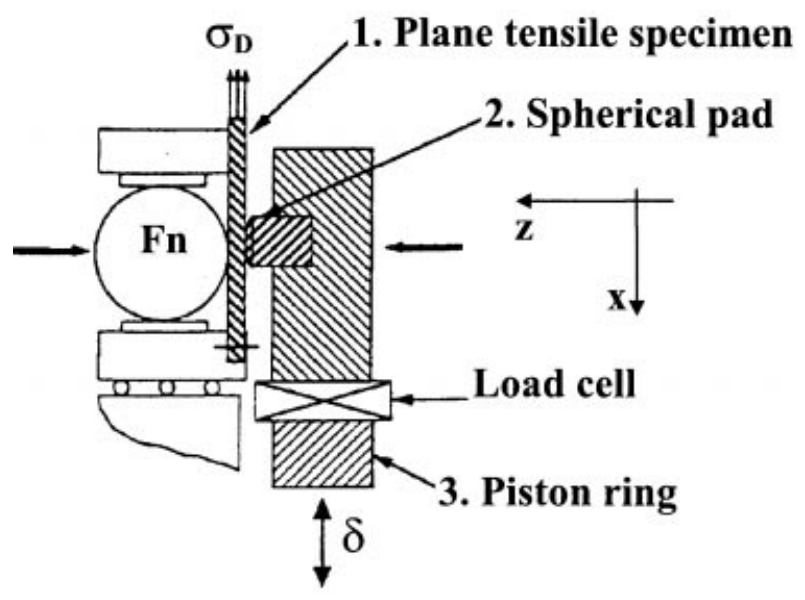

(b)

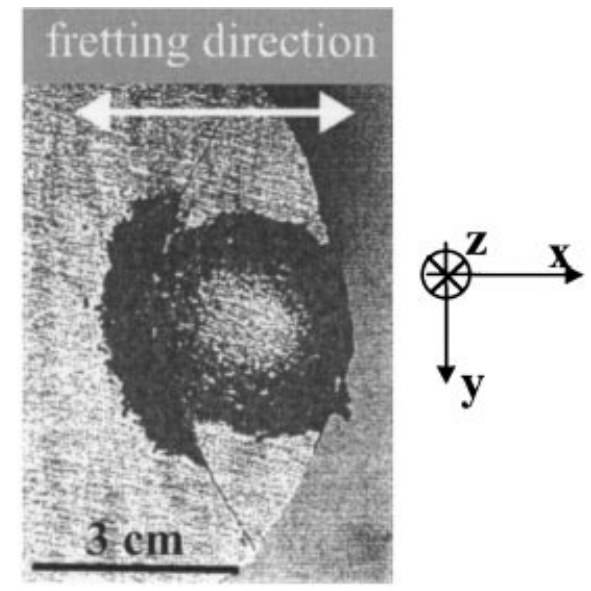

Fig. 1 Experimental device and results. (a) Experimental fretting apparatus. (b) Planar specimen contact surface and semielliptical crack trajectory.

cess. Two main cracks develop from this network, while most of the other cracks self-arrest. They propagate along a semielliptical trajectory [Figs 1(b) and 2(b)] at the contacting surface, and along two distinct directions during, respectively, Stage I and Stage II within the specimen depth (Fig. 3). The transition between these two periods is revealed by a crack branching along the Stage II propagation direction. Two types of cracks are observed (Fig. 3) during Stage I. Type I crack grows initially at a shallow angle to the specimen surface with a propagation direction ranging from $15^{\circ}$ to $35^{\circ}$ to the surface, and mainly occurs in the middle of the contact microsliding zone. Type II crack grows along a direction approximately perpendicular to the surface with a direction ranging from $75^{\circ}$ to $90^{\circ}$ to the surface, and appears near the edge of the contact area inside and/or outside the contact patch. Furthermore, it was observed that the nearer to the contact centre cracks initiate, the shallower
Meridian plane of the contact
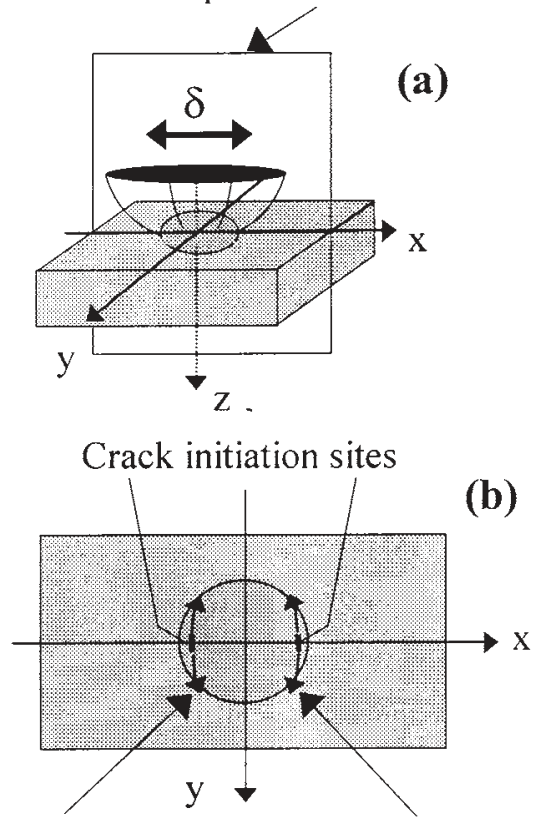

Crack propagation direction at the specimen surface

(d)
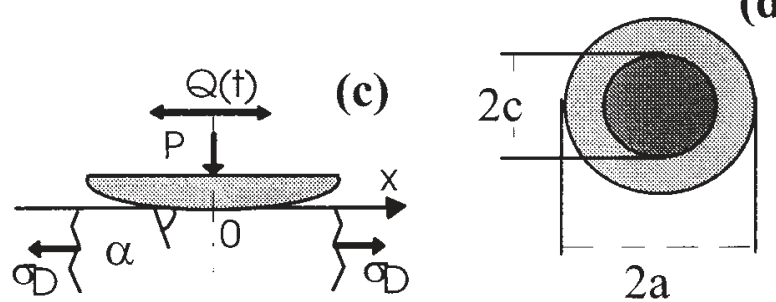

Fig. 2 Notations used by the model. (a) Definition of the meridian plane of the contact area. (b) Schematic position of crack initiation sites. (c) Notations in the contact model. (d) Contact zone notations.

to the surface the initial crack growth direction, for both crack types. Then, during Stage II, both types of crack propagate along a direction of $\approx 65^{\circ}$ to the surface. The transition from Stage I to Stage II is characterized by this change in propagation direction. The branching depth slightly varies, but the maximum crack length during Stage I does not exceed $160 \mu \mathrm{m}$. Furthermore, microscopic observations of cracked samples show that crack branching does not take place at a grain boundary.

\section{THEORETICAL APPROACH TO INITIAL CRACK GROWTH DURING STAGE I}

As a starting point, crack propagation is analysed in the meridian plane $y=0$ (Figs 1 and 2) where cracks first initiate, as a two-dimensional problem. An equivalent cylinder on plane contact is defined. ${ }^{10}$ This contact prob- 
(a)

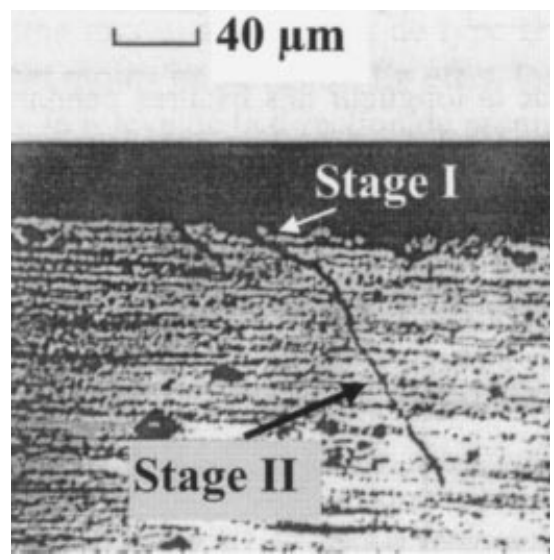

(b)

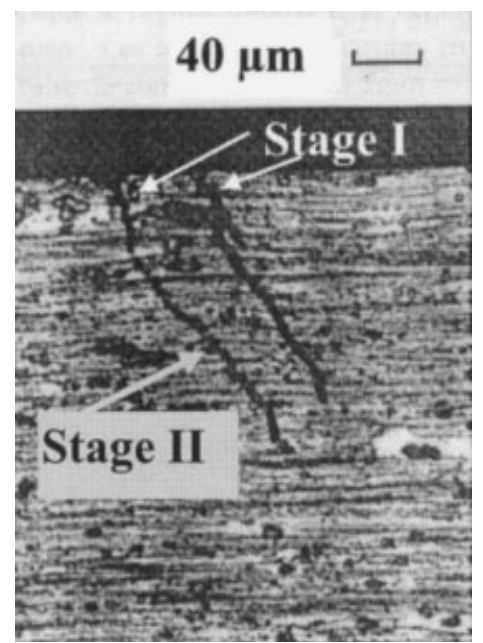

Fig. 3 Crack propagation direction during Stage I and Stage II. (a) Type I crack. (b) Type II crack.

lem is solved as a unilateral contact problem with friction, ${ }^{5}$ Coulomb's law being used. An incremental description of the tangential loading is used to account for the hysteresis phenomena. Contact area size, sequence of stick and microsliding zones in the contact area, normal and tangential traction distributions are determined (Fig. 2), as well as the subsurface stresses. Crack propagation during Stage I and crack branching mechanisms are investigated on the basis of the continuum stresses induced by the loading. As the stresses in the surface layer change steeply, average stresses are used, ${ }^{7}$ calculated along planes of length $L=$ $20 \mu \mathrm{m}$ (Fig. 4).

\section{Analysis of fretting fatigue crack propagation during Stage I}

The crack initiation mechanisms have been identified theoretically by employing a simple dislocation dipole (a)

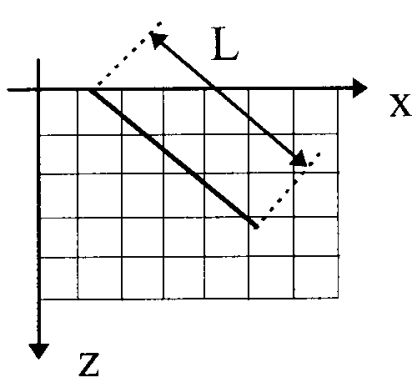

(b)

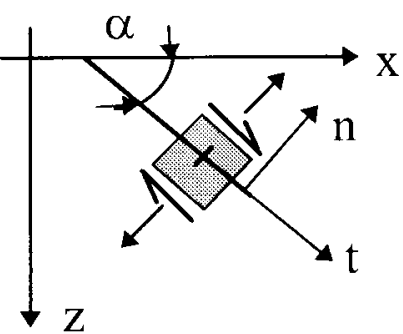

Fig. 4 Notations used for the stress field calculation. (a) Inclined line in the general calculation mesh $(x, z)$. (b) New coordinates $(n, r)$ linked to the inclined line.

model and taking into consideration the reverse sliding along two dislocation layers ${ }^{7,8}$ and the influence of the distance between these layers. ${ }^{11}$ It is shown that cracks may initiate either by an extrusion-intrusion mechanism or a fatigue tensile process. Two parameters, based on the amplitude of the average shear stress $\Delta \tau_{\mathrm{m}}$ and the average tensile stress $\sigma_{\mathrm{m}}$ perpendicular to the crack path, have been proposed. In the next section, initial crack growth directions and initiation sites will be predicted according to these specific parameters, and will be compared to experimental observations. Due to the loading symmetry and for the sake of brevity, the results are presented only for one side of the contact area $(x<0)$.

The type I crack is a shear mode fatigue crack. Its growth occurs macroscopically in the direction given by angle $\alpha$, along which the value of the shear driving force, i.e. the amplitude of the average shear stress, $\Delta \tau_{\mathrm{m}}$, is maximum $\Delta \tau_{\mathrm{m}}=\Delta \tau_{\mathrm{m}, \max }$, and such that the average value $\sigma_{\mathrm{a}}$ of the average tensile stress perpendicular to that direction, $\sigma_{\mathrm{m}}\left[\sigma_{\mathrm{a}}=0.5^{*}\left(\sigma_{\mathrm{m}, \max }+\sigma_{\mathrm{m}, \min }\right)\right]$ is minimum (an absolute value of $40 \mathrm{MPa}$ is considered here for this minimum). Owing to these two parameters, a single growth direction is predicted at each initiation site, ${ }^{12}$ whereas most of the existing criteria predict initial crack growth direction in the shear mode 7 along two theoretical initial directions. Further criteria for the type I crack initiation domain can be defined, and the risk is assumed to be the highest where $\sigma_{\mathrm{a}}$ is zero. The potential 
initiation loci $(-1.74,-1.64 \mathrm{~mm}$ and $1.64,1.74 \mathrm{~mm}$ due to loading symmetry) and the corresponding initial crack growth directions (from $35^{\circ}$ near the contact edge to $15^{\circ}$ near the contact stick zone) derived from this approach for the test configuration employed (Fig. 5) are in good agreement with the experimental results.

The type II crack is a tensile mode fatigue crack. Its nucleation is due to the presence of an initial flaw in the material, either pre-existing or created as a result of dislocation movements. The propagation driving force is assumed to be the maximum amplitude of crack opening. The crack extension angle $\alpha$ is therefore defined by the direction along which the 'effective' amplitude of the average stress normal to the crack trajectory $\Delta \sigma_{\mathrm{m}}^{*}$ is maximum, $\Delta \sigma_{\mathrm{m}}^{*}=\Delta \sigma_{\mathrm{m} \text {,max }}^{*}$ (Fig. 6). Further, the amplitude of the average shear stress tends to a minimum value along that direction. Type II crack location is therefore near the edge of the contact area, inside or just outside it, where a high level of tensile stress occurs.

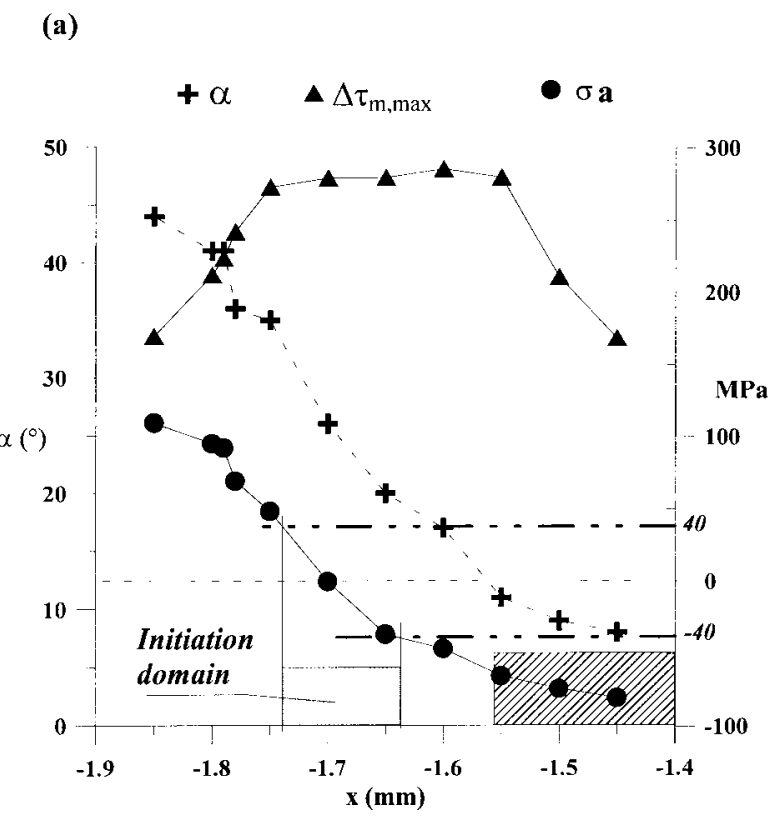

(b)

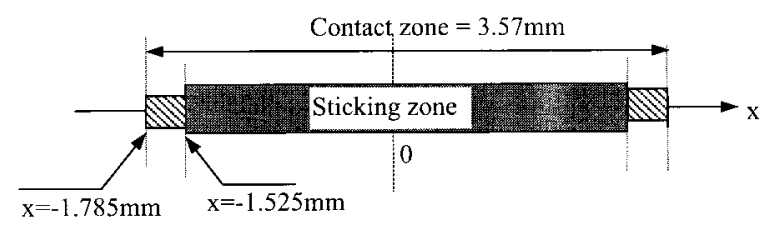

Fig. 5 Determination of initial type I crack growth directions and corresponding initiation sites. (a) Variations of $\Delta \tau_{\mathrm{m}, \max }, \sigma_{\mathrm{a}}$ and $\alpha$ defined by $\Delta \tau_{\mathrm{m} \text {,max }}$ versus contact abscissa $x$. (b) Repartition of sticking and microsliding zones in the contact area. (a)

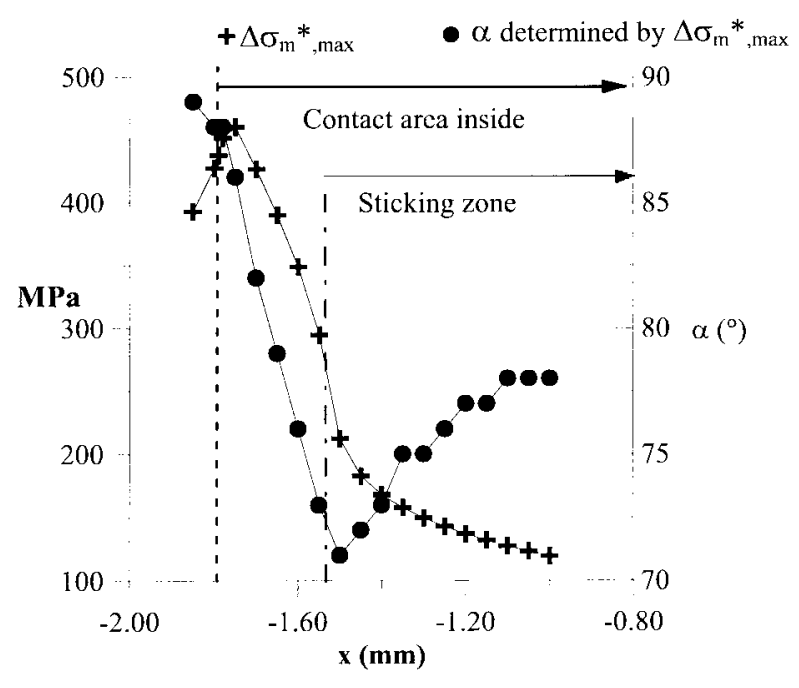

(b)

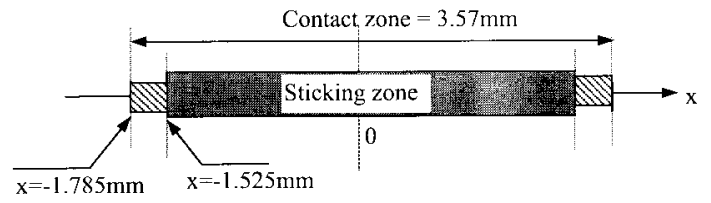

Fig. 6 Determination of initial type II crack growth direction and corresponding initiation sites. (a) Variations of $\Delta \tau_{\mathrm{m}, \max }^{*}$ and $\alpha$ defined by $\Delta \sigma_{\mathrm{m}, \max }^{*}$ versus contact abscissa $x$. (b) Repartition of sticking and microsliding zones in the contact area.

Angle $\alpha$ thus ranges from $90^{\circ}$ (outside the contact patch) to $70^{\circ}$ inside the contact zone. These crack inclinations and locations correlate very well with the experimental observations on type II cracks. Here again, the nearer cracks initiate with respect to the contact centre, the nearer to the surface cracks propagate.

\section{Crack network initiation}

Type I and II crack initiation domains are now defined in which the most favourable point of initiation can be determined. For type I shear cracks, this location is where $\sigma_{\mathrm{a}}$ is exactly equal to zero, while for type II tensile crack, it is where $\Delta \sigma_{\mathrm{m}}^{*}$ reaches the maximum value $\Delta \sigma_{\mathrm{m} \text {,max }}^{*}$. These two sites are encircled by regions in the material which are also submitted to favourable conditions for crack initiation. A crack initiation scenario can thus be proposed. Once a crack has initiated at the most favourable site, its propagation unloads temporarily the neighbouring contact points, modifying locally the contact conditions through crack flank movements, and 
as a consequence, the specimen stiffness. Parameters inducing crack initiation and propagation are less efficient in the crack vicinity leading to a delay in the development of the crack network. Furthermore, the various inclinations of cracks in the crack network can lead to spall detachment as cracks connect under the contact area. ${ }^{13}$

\section{ANALYSIS OF BRANCHING FROM STAGE I TO STAGE II}

Propagation transition from Stage I to Stage II is experimentally revealed by the branching of both crack types along the same direction of $\approx 65^{\circ}$ to the contact surface. The variations of the specific parameters identified as the propagation driving forces for each crack type are now analysed versus depth in order to understand the crack branching, and more specifically, issues, e.g. the branching depth, mode and direction of crack propagation after branching.

\section{Type I shear crack transition}

A type $\mathrm{I}$ crack $\left(\alpha=26^{\circ}\right)$ initiated at point $x=-1.70 \mathrm{~mm}$ in the contact area is considered. Figure 7 shows the

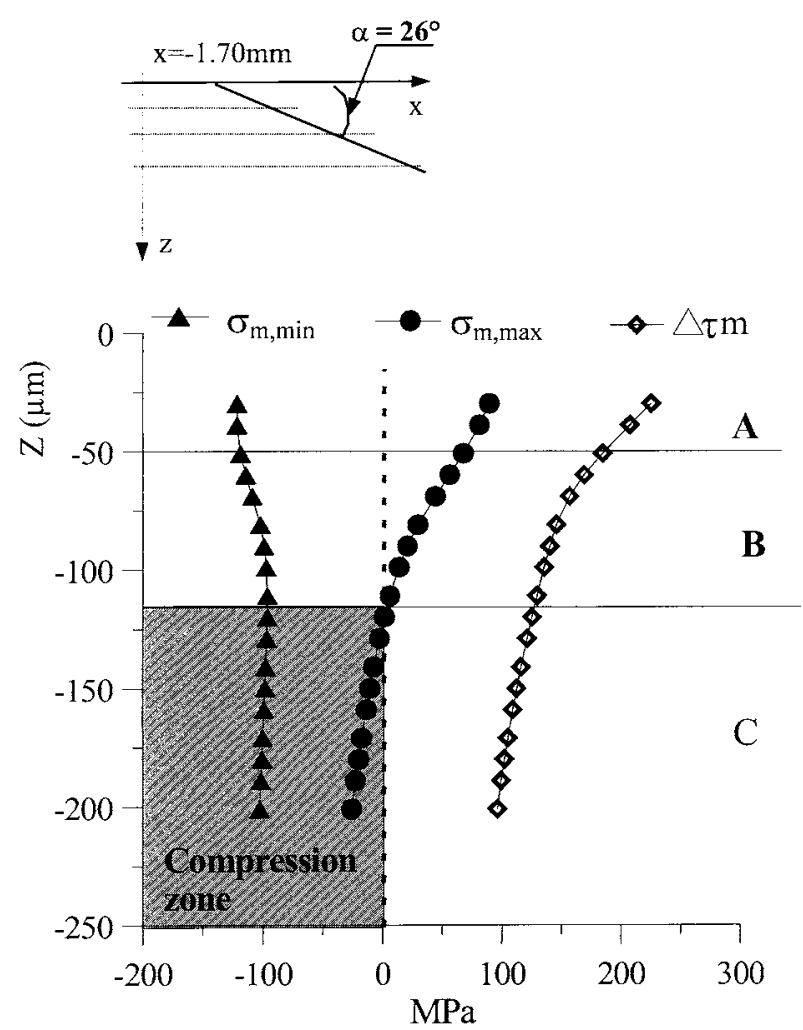

Fig. 7 Evolutions versus depth, $z$, of $\sigma_{\mathrm{m}, \min }, \sigma_{\mathrm{m}, \max }$ and $\Delta \tau_{\mathrm{m}}$ along the path of type I crack initiated at site $x=-1.70 \mathrm{~mm}$ and propagating along a direction of $26^{\circ}$ to the surface.
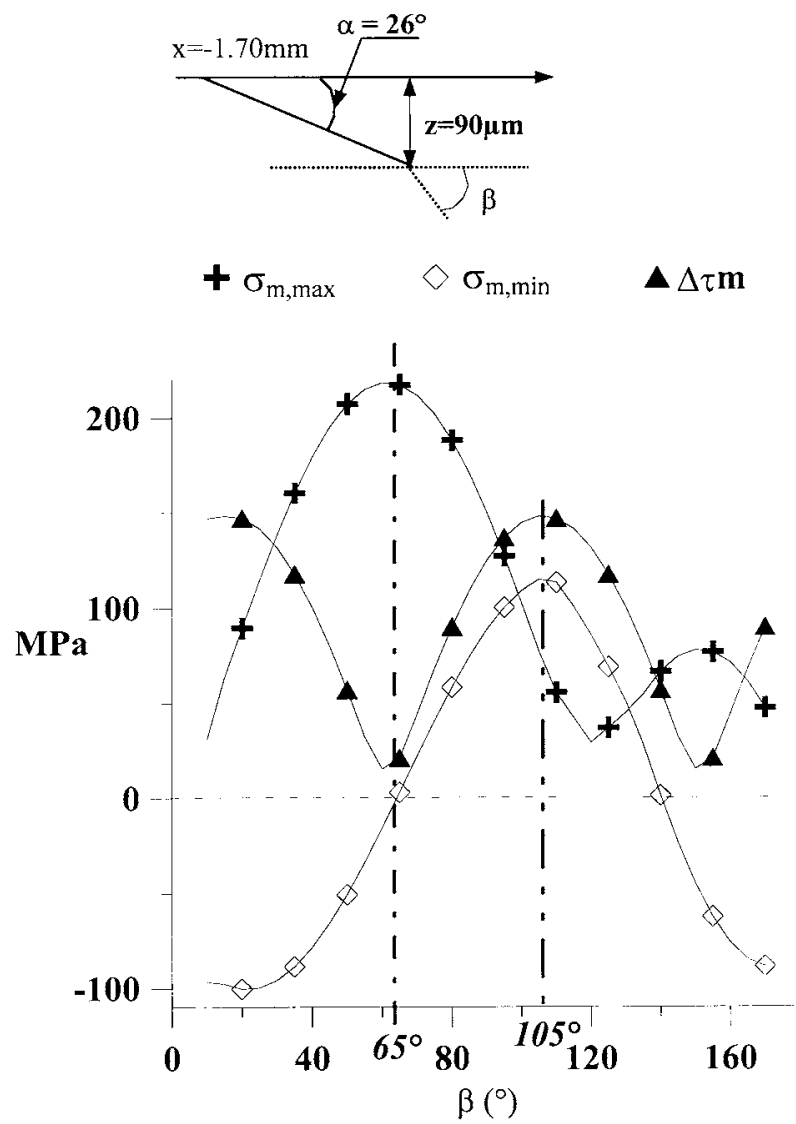

Fig. 8 Evolutions of $\sigma_{\mathrm{m}, \mathrm{min}}, \sigma_{\mathrm{m}, \mathrm{min}}$ and $\Delta \rho_{\mathrm{m}}$ versus inclination $\beta$ at depth $z=90 \mu \mathrm{m}$ at the tip of a type I crack initiated at site $x=$ $-1.70 \mathrm{~mm}$ and propagating along a direction of $26^{\circ}$.

evolution of $\sigma_{\mathrm{m}, \max }, \sigma_{\mathrm{m} \text {,min }}$ and $\Delta \tau_{\mathrm{m}}$ evaluated perpendicularly and along the propagation path $\alpha$, respectively, as a function of depth, $z$. Branching appears to be the consequence of different phenomena occurring simultaneously. Thus, the initial shear mode is progressively hindered as $\Delta \tau_{\mathrm{m}}$ is rapidly decreasing with depth, while $\sigma_{\mathrm{m}}$ normal to the crack path is becoming more and more compressive, thereby inducing crack-locking effects. Three zones A-C are defined versus depth with regard to the roles of $\Delta \tau_{\mathrm{m}}$ and $\sigma_{\mathrm{m}}$. In zone $\mathrm{A}, 0<z<50 \mu \mathrm{m}$, the shear mode propagation mechanism is activated, but $\Delta \tau_{\mathrm{m}}$ decreases rapidly, and simultaneously, $\sigma_{\mathrm{m}}$ becomes more and more compressive. In zone C, $z>110 \mu \mathrm{m}$, the shear mode propagation is stopped due to crack-locking effects ( $\sigma_{\mathrm{m}}$ is compressive over all the cycle), and $\Delta \tau_{\mathrm{m}}$ is reduced to $50 \%$ of its initial value just after initiation. Thus, crack branching is likely to occur in zone B where $50 \mu \mathrm{m}<z<110 \mu \mathrm{m}$. These depths are of the same order of magnitude as the experimental values.

The next issue is to determine the crack propagation mode and direction after branching. Propagation driving forces are analysed again. The argument is presented here for a branching which is suggested to occur at a 
depth of $90 \mu \mathrm{m}$ along a direction $\beta$ (Fig. 8). The results (mode and direction) are independent of the branching depth considered. The assumption of a Stage II propagation occurring due to a shear mode has been rejected: the new direction $\left(\beta=105^{\circ}\right)$ does not lead to an increase in $\Delta \tau_{\mathrm{m}, \max }$ value when compared to the value before branching, and above all, the stress normal to the crack path $\sigma_{\mathrm{m}}$ is tensile over all the load cycle. The type I crack branches to enhance its own propagation and to propagate according to mode $\mathrm{I}$. The value of $\Delta \sigma_{\mathrm{m}}^{*}$ is a maximum perpendicular to the direction $\beta=65^{\circ}$ (Fig. 8) to the surface, and $\Delta \tau_{\mathrm{m}}$ reaches a minimum value along that direction. The Stage II open mode propagation mechanism is here optimized through the minimization of shear mode influence.

\section{Type II tensile crack transition}

Observations show that type II cracks branch in the same Stage II direction $\left(\beta=105^{\circ}\right)$ as type I cracks. It is concluded that the Stage II propagation mechanism is also an opening mode with negligible shear mode effects. We will now analyse why the initial type II cracks propagating in an opening mode branch to propagate in another opening mode.

A type II crack $\left(\alpha=86^{\circ}\right)$ initiated at point $x=$ $-1.75 \mathrm{~mm}$ is considered. The values of $\sigma_{\mathrm{m}, \max }, \sigma_{\mathrm{m}, \min }$ and $\Delta \tau_{\mathrm{m}}$ are reported in Fig. 9 as a function of depth. As for type I cracks, branching is also the consequence of different phenomena. First of all, the predominant influence of the opening mode decreases progressively as the crack extends, while the shear mode influence on the propagating crack increases, and the initial type II crack gradually reverts to a mixed mode I + II crack. The values of $\Delta \sigma_{\mathrm{m}}^{*}$ normal to crack path $\alpha$ decrease gradually with depth, while $\Delta \tau_{\mathrm{m}}$ increases gradually along the $\alpha$ direction. Further, mode I conditions are better fulfilled according to a new direction $\beta$ from the depth of $95 \mu \mathrm{m}: \Delta \sigma_{\mathrm{m}}^{*}$ is greater normal to $\beta$ than perpendicularly to $\alpha=86^{\circ}$ (Fig. 10) and $\Delta \tau_{\mathrm{m}}$ along $\beta$ is minimized. The branching depth and the Stage II propagation direction correlate very well with the experimental observations.

Hence, under fretting conditions, Stage I type I and II cracks branch towards the same Stage II direction where the effective amplitude of traction $\Delta \sigma_{\mathrm{m} \text {,max }}^{*}$ is maximum. The new propagation direction $\beta$ is the direction optimizing the amplitude of crack opening and minimizing the participation of shear mode in the propagation mechanism.

Hence, the branching of type II cracks is not, contrary to type I branching, a consequence of a radically new propagation mode. Initial type II cracks branch in a new direction more favourable to the initial mode I propagation mechanism.

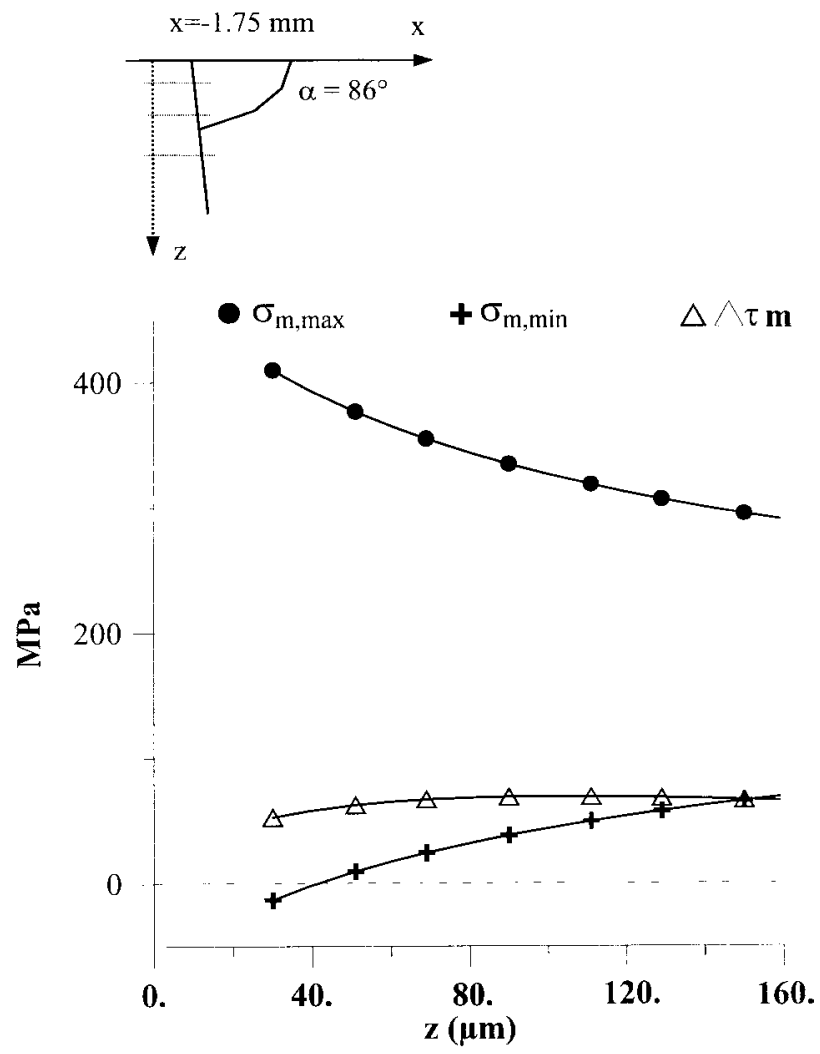

Fig. 9 Evolutions versus depth $z$ of $\sigma_{\mathrm{m}, \max }, \sigma_{\mathrm{m}, \min }$ and $\Delta \tau_{\mathrm{m}}$ for a type II crack initiated at site $x=-1.75 \mathrm{~mm}$ and propagating along a direction of $86^{\circ}$ to the surface.

Hence, under fretting conditions, both types of initial cracks branch towards the same Stage II direction where the effective amplitude of the tensile stress $\sigma_{\mathrm{m}}$ is maximum. The new propagation direction is not related to the maximum crack opening, but to the maximum amplitude of crack opening. This amplitude is actually more characteristic to fatigue phenomena. This direction also corresponds to the minimum participation of shear mode during crack propagation.

\section{CONCLUSIONS}

A theoretical model is developed to predict the initial crack growth direction during Stage I, and subsequent branching from Stage I to Stage II, under fretting conditions. The continuum stress field is analysed for conditions where the cracks observed are small enough not to extensively disturb the stress field. This model is based on the analysis of conditions favouring Stage I crack propagation. Through an analysis of stresses acting along and perpendicular to the crack path, cracks were shown to grow during Stage I along two possible distinct directions. 


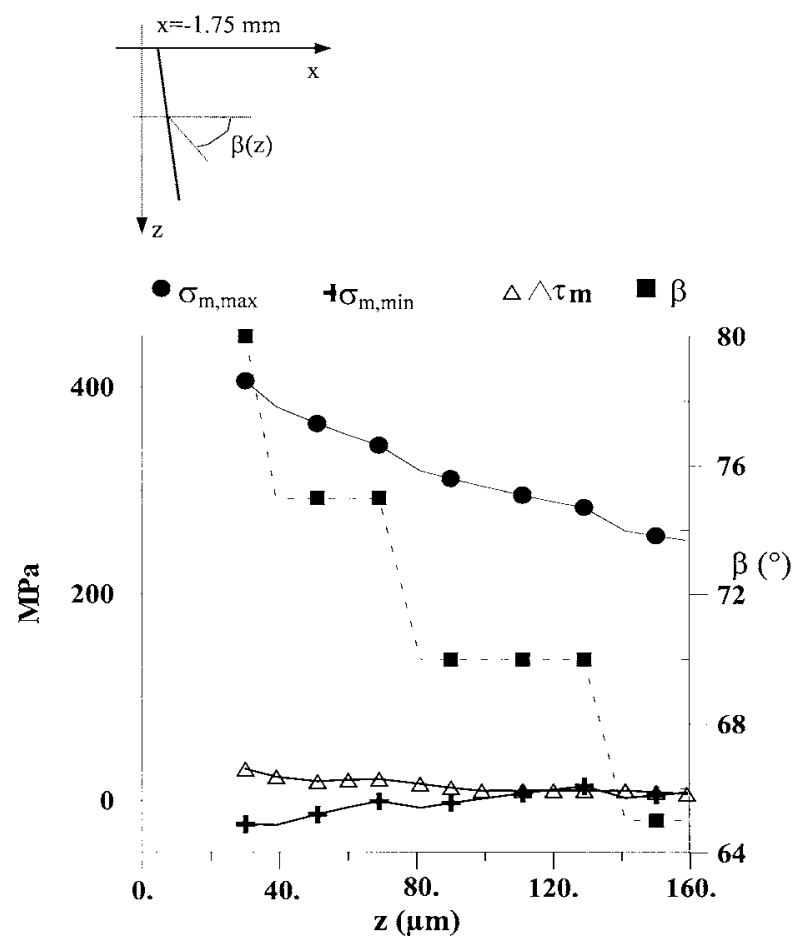

Fig. 10 Evolutions versus depth $z$ of $\beta(z)$ defined by $\sigma_{\mathrm{m}, \max }$, and of $\sigma_{\mathrm{m}, \max }, \sigma_{\mathrm{m}, \min }$ and $\Delta \tau_{\mathrm{m}}$, respectively, perpendicularly and along direction $\beta(z)$, at the tip of a type II crack initiated at site $x=$

$-1.75 \mathrm{~mm}$ and propagating along a direction of $86^{\circ}$ to the surface.

1 A direction ranging from $15^{\circ}$ to $35^{\circ}$ to the contact surface. These type I cracks were shown to initiate in the middle of the contact microsliding zone. As experimentally observed, it was predicted that the nearer the cracks initiate to the contact centre, then the nearer they propagate to the contact surface. This first crack (of type I) develops during Stage I in a shear mode. The amplitude of shear stress is the driving force during this Stage I propagation period. The tensile stress perpendicular to the crack trajectory favours this propagation. Contrary to general initiation criteria, the model enables us to predict a single initiation plane by taking into account the influence of both the shear stress and normal stress on the crack trajectory.

2 A direction ranging from $75^{\circ}$ to $90^{\circ}$ to the contact surface. These (type II) cracks were shown to initiate near the contact edge in and/or outside the contact patch. Here again, it was predicted that the nearer the cracks initiate to the contact centre, then the nearer to the contact surface the cracks progress. This second crack type propagates during Stage I in an opening mode. The effective amplitude of the normal stress is the governing factor during Stage I.
Finally, the conditions governing crack branching from Stage I to Stage II were identified. It was shown that both initial crack types (I and II) branch as a consequence of the following.

1 The decrease of Stage I propagation driving force. Each crack type propagation mode (shear and opening) gradually turns to a mixed I + II mode. Furthermore, crack locking effects gradually hinder type I crack propagation.

2 Concomitantly, the increase of the effective amplitude of the tensile stress perpendicular to the direction of $65^{\circ}$ to the contact surface. Along that same direction, the influence of shear mode is minimized. Hence, branching and initial propagation during Stage II are governed by the maximum amplitude of the crack opening and not by its maximum value.

\section{REFERENCES}

1 L. Vincent, Y. Berthier and M. Godet (1992) Testing methods in fretting fatigue: a critical appraisal. ASTM-STP 1159, 33-48.

2 K. Van Dang, B. Griveau and O. Message (1989) On a new multiaxial fatigue limit criterion: theory and applications. In: Biaxial and Multiaxial Fatigue (Edited by M. W. Brown), Mechan Engineering Publications, London, pp. 479-496.

3 C. Ruiz, P. H. B. Boddington and K. C. Chen (1984) An investigation of fatigue and fretting in a dovetail joint. Exp. Mech. 24, 208-217.

4 D. A. Hills and D. Nowell (1994) Mechanics of Fretting Fatigue. Kluwer Academic, Dordrecht, 236 pp.

5 V. Lamacq, M.-C. Dubourg and L. Vincent (1996) Crack path prediction under fretting fatigue- $\mathrm{a}$ theoretical and experimental approach. ASME 7. Tribol. 118, 711-720.

6 D. Nowell, D. A. Hills and J. J. O'Connor (1987) An analysis of fretting fatigue. In: Proceedings Instn. Mech. Engrs, pp. 965-973.

7 N. Yamashita and T. Mura (1983) Fatigue crack initiation under repeated oblique force. Wear $\mathbf{9 1}, 235-250$.

$8 \mathrm{~K}$. Tanaka and T. Mura (1981) A dislocation model for fatigue crack initiation. 7. Appl. Mech. 47, 111-113.

9 P. Reybet Degat, Z. R. Zhou and L. Vincent (1996) Fretting behavior on pre-stressed aluminium alloy specimen, Trib. Int. 30(3), 711-720.

10 T. Mura and Y. Nakasone (1990) A theory of fatigue crack initiation in solids. 7. Appl. Mech. 57, 1-6.

11 V. Lamacq, M.-C. Dubourg and B. Villechaise (1996) Fretting fatigue crack growth analysis-experimental photoelastic method combined with numerical model. In: ECF 11, Mechanisms and Mechanics of Damage and Failure, Poitiers, 3-6 Septembre, pp. 1387-1392.

12 V. Lamacq, M.-C. Dubourg and L. Vincent (1997) A theoretical model for the prediction of initial growth angles and sites of fretting fatigue cracks. Trib. Int. 30(6), 391-400.

13 V. Lamacq (1997) Amorçage et propagation de fissures de fatigue sous conditions de fretting-approches théorique et expérimentale. PhD thesis, INSA de Lyon, $252 \mathrm{pp}$. 